УДК 539.3

\author{
Є. А. Макаренков, А. В. Сясєв
}

Дніпровський начіональний університет імені Олеся Гончара

\title{
ТЕРМОНАПРУЖЕНИЙ СТАН ПРОСТОРОВИХ КОНСТРУКЦЙ НА ПРИКЛАДІ ФУНДАМЕНТІВ ТУРБОГЕНЕРАТОРІВ АТОМНОЇ ЕЛЕКТРОСТАНЦІї
}

На атомних станціях застосовуються тихохідні енергоблоки потужністю 1000 мегаватт 3 частотою обертання ротора 1500 обертів на хвилину. Ці турбогенератори відносяться до групи машин періодичної дії, у яких вид головного руху - рівномірне обертання. В процесі експлуатації турбогенераторів вказаної потужності виявилося необхідність розв'язку цілого ряду складних питань взаємодії системи турбогенератор - фундамент - основа 3 метою розробки заходів, що забезпечують високу надійність експлуатації такої системи. У цих енергоблоків с ряд особливостей, які не дозволяють застосовувати поширені рамні фундаменти, внаслідок чого були створені нові типи фундаментів спеціально для потужних тихохідних турбогенераторів. Такі турбогенератори мають великі геометрині розміри і маси обертових частин. Все це призводить до того, що валопроводи таких турбогенераторів вельми чутливі до самих малих відносних зміщень опор, які викликають його розцентрування i, як наслідок, призводять до порушення нормального режиму експлуатації турбогенератора, i, в цілому ряді випадків, до аварійної зупинки. В період експлуатації турбогенератора на його розцентрування впливають різні фактори. Найбільш істотним с деформація фундаменту в результаті нерівномірних осадів підстави, а також температурна деформація конструкції.

3 використанням методу скінченних елементів розроблено математичну модель розрахунку термонапруженого стану просторових конструкцій типу фундаментів турбогенераторів в різних умовах експлуатації енергетичного обладнання. Розглядалася просторова квазістатична задача визначення термонапруженого стану фундаментної конструкції. Розв'язок задачі базувався на принципі незалежності теплових і механічних впливів. Наведено результати розрахункового та експериментального дослідження на прикладі фундаментів під діючі турбогенератори атомної електростанції.

Ключові слова: термонапружений стан, фундаментна конструкція, теплопровідність, граничні умови, дискретна модель, матриця, метод скінченних елементів.

На атомных станциях применяются тихоходные энергоблоки мощностыю 1000 мегаватт с частотой вращения ротора 1500 оборотов в минуту. Эти турбогенераторы относятся к группе машин периодического действия, у которых вид главного движения - равномерное вращение. В ходе эксплуатации турбогенераторов указанной мощности выявилась необходимость решения целого ряда сложных вопросов взаимодействия системы турбогенератор - фундамент основание с целью разработки мероприятий, обеспечивающих высокую надежность эксплуатации такой системы. У этих энергоблоков имеются ряд особенностей, которые не позволяют применять распространенные рамные фундаменты, вследствие чего были созданы новые типы фундаментов специально под мощные тихоходные турбогенераторы. Такие турбогенераторы имеют значительные геоетрические размеры и массы вращающихся частей. Все это приводит к тому, что валопроводы таких турбогенераторов весьма чувствительны к самым малым относительным смещениям опор, вызывающим его расцентровку и, как следствие, приводящим к нарушению нормального режима эксплуатации турбогенератора, а, в целом ряде случаев, к аварийному останову. В период эксплуатации турбогенератора на его расцентровку оказывают влияние различные факторы. Наиболее существенным является деформация фундаментов в результате неравномерных осадок основания, а также температурная деформация конструкции.

С использованием метода конечных элементов разработана математическая модель расчета термонапряженного состояния пространственных конструкций типа фундаментов турбогенераторов в различных условиях эксплуатации энергетического оборудования.

(C) Макаренков Є. А., Сясев А. В., 2019 
Рассматривалась пространственная квазистатическая задача определения термонапряженного состояния фундаментной конструкции. Решение задачи основывалось на принципе независимости тепловых и механических воздействий. Приведены результаты расчетного и экспериментального исследования на примере фундаментов под действующие турбогенераторы атомной электростанции.

Ключевые слова: термонапряженное состояние, фундаментальная конструкция, теплопроводность, граничные условия, дискретная модель, матрица, метод конечных элементов.

Low speed power units with a capacity of 1000 megawatts and a rotor speed of $1500 \mathrm{rpm}$ are used at nuclear power plants. These turbogenerators belong to the group of batch machines in which the form of the main movement is uniform rotation. During the operation of the turbogenerators of the indicated capacity, the need emerged to solve a number of complex issues of interaction between the turbogenerators - foundation - system and the foundation on with the aim of developing measures ensuring the high reliability of the operation of such a system. These power units have a number of features that do not allow the use of common frame foundations, as a result of which new types of foundations were created specifically for powerful low speed turbogenerators. Such turbogenerators have significant geometric dimension and masses of rotating parts. All this leads to the fact that the shaft lines of such turbogenerators are very sensitive to the smallest relative displacements of the supports, cansing its misalignment and, as a result, leading to a violation of the normal operating mode of the turbogenerator, and in a number of cases to emergency shutdown. During the operation of the turbogenerator, various factors influence the alignment. The most significant is the deformation of the foundation as a result of uneven settlement of the base, as well as thermal deformation of the structure.

Using the finite element method, a mathematical model has been developed for calculating the thermally stressed state of spatial structures such as the foundations of turbogenerators in various operating conditions of power equipment. Considered the spatial quasistatic problem of determining the thermally stressed state of the foundation structure. The solution of the problem was based on the principle of independence of thermal and mechanical effects. The results of computational and experimental studies are given on the example of foundations for operating turbogenerators of a nuclear power plant.

Keywords: thermal stress state, foundation structure, heat transfer, boundary conditions, discrete model, matrix, finite element method.

Вступ. Дотримання безпечної експлуатації технологічного обладнання є одним із найважливіших завдань сучасної інженерії для забезпечення надійної роботи інженерно-технологічних галузей економіки індустріальної держави.

Сучасні тенденції розвитку інженерної практики свідчать, що першочерговою $€$ проблема контролю за термонапруженим станом елементів конструкції та одночасно забезпечення таких умов перебігу експлуатації, за яких унеможливлюється виникнення небажаного внутрішнього термонапруженого стану з погляду міцності, жорсткості та стійкості.

Розглядаючи фундаментальну конструкцію турбогенератора, можна зробити висновок, що вона представляє собою просторову конструкцію великої протяжності. До iї складу входять гнучкі колони, жорсткі поперечні балки та поперечні монолітні стіни, колони та стіни з'єднують між собою верхні та нижні будівлі.

Для нормальної експлуатації таких конструкцій велике значення має дослідження термонапруженого стану, тому що збільшення сезонних та експлуатаційних осад фундаменту на два, три міліметри може призвести до розцентровки валопроводу турбогенератора та викликати аварійне зупинення енергоблока.

Для прогнозування порушення робочих режимів експлуатації турбогенератора виникає необхідність визначення критичного термонапруженого стану елементів фундаментної конструкції.

Аналіз останніх досліджень та публікацій. У роботі [7] запропоновано в загальному вигляді математичну модель розрахунку термонапруженого стану конструкції складного профілю. У статті [2] йдеться про математичну модель теорії 
пластичності, яка має додаткову складність за рахунок нелінійної залежності напружень та деформацій. Для числової реалізації заданої пластичності пропонується використати метод скінченних елементів. В [1] викладено актуальні питання використання різних типів сіток, які використовуються при апроксимації перетинів будівельних конструкцій, поперечних до напрямку сталості їх фізикогеометричних характеристик, описано основні етапи реалізації дискретноконтинуального методу скінченних елементів. Числове моделювання задач лінійної пружності на однорідній області розглядається в [9], крім того тут наведено загальну постановку та алгоритм розв'язку стаціонарних задач лінійної пружності однорідного ізотропного тіла. На прикладі двомірної модельної задачі досліджується вплив розмірів осередків обчислювальної сітки та степінь поліному використаних скінченних елементів на точність розв'язку задачі. У статті [2] розглянуто питання виникнення термонапруженого стану в елементах конструкцій, застосовних у машинобудуванні. Отримано аналітичний розв'язок нестаціонарної задачі визначення термонапруженого стану з граничними умовами першого роду для двохзв'язної області елемента конструкції типу циліндра. Використання методу скінченних елементів для розв'язання нелінійної нестаціонарної задачі теплоелектропровідності розглянуто в роботі [4].

Мета дослідження. Метою дослідження $\epsilon$ розробка методу розрахунку термонапруженого стану просторових конструкції типу фундаментів турбогенераторів атомних електростанцій.

Основний матеріал дослідження. Розглянуто квазістатичну просторову незв'язану задачу визначення термонапруженного стану.

Вважаємо, що фізико-математичні характеристики матеріалу ортотропні. Для розв'язання задачі використовується принцип незалежності теплових і механічних впливів, тобто окремо розв'язувалась задача теплопровідності, а потім для визначеного температурного поля у фіксований момент часу визначено термонапружений стан.

Визначення температурного поля зводилося до розв'язання стаціонарного рівняння теплопровідності у декартовій системі координат з граничними умовами першого та третього роду [7].

У векторній формі рівняння теплопровідності має вид

$$
\operatorname{div}\left(\lambda^{T} \operatorname{grad} t\right)+Q=0
$$

Для розв'язання рівняння (1) 3 граничними умовами [7] залучимо метод скінченних елементів (МСЕ) у поєднанні з методом Гальоркіна [10].

Розв'язок цієї задачі еквівалентний розв'язку інтегрального рівняння [7].

Для всієї конструкції в цілому це інтегральне рівняння має вигляд

$$
\sum_{e=1}^{E}\left\{\int_{V}\left[N^{e}\right]^{T}\left[\operatorname{div}\left(\lambda^{T} \operatorname{grad} t\right)+Q\right] d V-\int_{S}\left[N^{e}\right]^{T}\left(\lambda^{T} \frac{\partial t}{\partial n}\right) d S-\int_{S}\left[N^{e}\right]^{T}[\alpha(t-\theta)] d S\right\}=0,
$$

де $E$ - число елементів, $T$ - індекс транспонування, $N^{(e)}-$ функції форми, $\alpha, \theta-$ відповідно коефіцієнти теплообміну та температура навколишнього середовища, $V$ - об'єм скінченого елемента, $S$ - поверхня елемента. 
Далі обираємо $N^{(e)}$ та перетворюємо інтеграли з (2) так, щоб вони містили похідні від невідомої функції не вище першого порядку. Потім скорочуємо порядок диференціальних співвідношень, використовуючи теорему Гауса [10].

В результаті рівняння (2) набуває вигляду

$$
\int_{V} N_{\beta, i}\left\lfloor\lambda^{T} \operatorname{grad} t\right] d V-\int_{V} N_{\beta} Q d V-\int_{S} N_{\beta}[\alpha(t-\theta)] d S=0,
$$

де $Q$ - внутрішнє джерело, обумовлене складними фізико-хімічними процесами, що відбуваються при зміні агрегатного стану бетону, $N_{\beta, i}$ - похідні функцій форми за координатами.

Дискретна модель для розв'язання задачі МСЕ представляє собою кубічний елемент (рис. 1), до якого прив'язувалася локальна система координат $x^{\prime}, y^{\prime}, z^{\prime}, 3$ початком у центрі ваги елемента $O\left(x_{u \ell}, y_{u в}, z_{u в}\right)$.

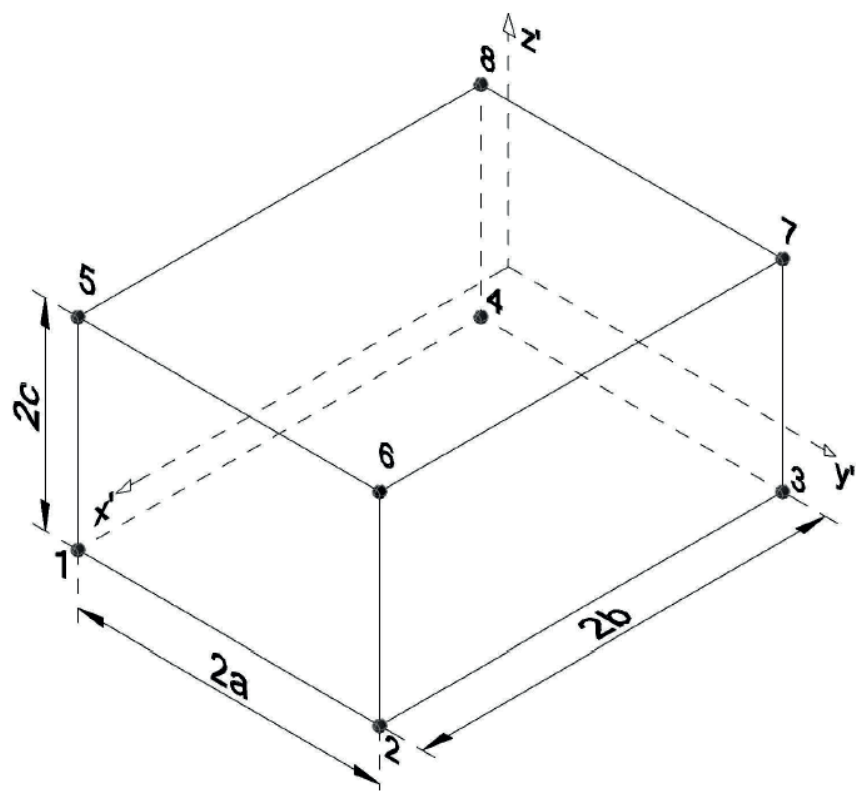

Рис. 1. Кубічний елемент дискретної моделі

Визначення температурних полів в елементах зводиться до розв'язання системи алгебраїчних рівнянь у матричному виді $\left.\mid K^{(e)}\right] \cdot\left\{t_{i}\right\}=\left\{f^{(e)}\right\}$. Тут матриця $\left[K^{(e)}\right\rfloor$ має вигляд

$$
\left[K^{(e)}\right]=\int_{V^{e}}\left[B^{(e)}\right]^{T}\left[D^{(e)}\right]\left[B^{(e)}\right] d V+\int_{S^{e}} \alpha\left[N^{(e)}\right]^{T}\left[N^{(e)}\right] d S
$$

і визначає матрицю теплопровідності; вектор правих частин для елемента

$$
\left[f^{(e)}\right]=\int_{V^{e}} Q\left[N^{(e)}\right]^{T} d V+\int_{S^{e}} \alpha \theta\left[N^{(e)}\right]^{T} d S
$$

визначає вектор теплового навантаження, $\left\{\mathrm{t}_{\mathrm{i}}\right\}$ - вектор вузлових значень температур для задачі, що розглядається $i=1, \ldots, 8$. 
У співвідношенні (3) $\left|N^{(e)}\right|$ представляє собою матрицю функцій форми для елемента з номером $(e),\left[B^{(e)}\right\rfloor$ - матриця, яка отримана диференціюванням матриці $\left\lfloor N^{(e)}\right\rfloor$

$$
\left[D^{(e)}\right]=\left|\begin{array}{ccc}
\lambda_{x}^{T} & 0 & 0 \\
0 & \lambda_{y}^{T} & 0 \\
0 & 0 & \lambda_{z}^{T}
\end{array}\right| .
$$

Для розв'язання задачі було вибрано скінченний елемент розміром $2 a, 2 b, 2 c$ (рис. 1); матриця функцій форми для нього обирається так, як у [10].

Розглянемо принцип побудови поверхневих елементів у співвідношеннях (3) i (4). Поверхневий інтеграл у співвідношенні (3) описує конвективний теплообмін на поверхні скінченного елемента. Наприклад, якщо конвективний теплообмін має місце на грані, котра обмежена поверхнею з вузлами 1, 2, 3,4 (рис. 1) та її формула $z=-c$, а функції форми $N_{5}=N_{6}=N_{7}=N_{8}=0$, то в цьому випадку поверхневий інтеграл при $\alpha=$ const записується наступним чином

$$
\begin{gathered}
\alpha \int\left|\begin{array}{cccccccc}
N_{1}^{2} & N_{1} N_{2} & N_{1} N_{3} & N_{1} N_{4} & 0 & 0 & 0 & 0 \\
N_{1} N_{2} & N_{2}^{2} & N_{2} N_{3} & N_{2} N_{4} & 0 & 0 & 0 & 0 \\
N_{1} N_{3} & N_{2} N_{3} & N_{3}^{2} & N_{3} N_{4} & 0 & 0 & 0 & 0 \\
N_{1} N_{4} & N_{2} N_{4} & N_{3} N_{4} & N_{4}^{2} & 0 & 0 & 0 & 0 \\
0 & 0 & 0 & 0 & 0 & 0 & 0 & 0 \\
0 & 0 & 0 & 0 & 0 & 0 & 0 & 0 \\
0 & 0 & 0 & 0 & 0 & 0 & 0 & 0 \\
0 & 0 & 0 & 0 & 0 & 0 & 0 & 0
\end{array}\right| d S, \\
\text { де } N_{1}=\frac{1}{4 a b}(b+x)(a-y), N_{2}=\frac{1}{4 a b}(b+x)(a+y), N_{3}=\frac{1}{4 a b}(b-x)(a+y) \text {, } \\
N_{4}=\frac{1}{4 a b}(b-x)(a-y) .
\end{gathered}
$$

Якщо конвективний теплообмін має місце на грані з вузлами 5, 6, 7,8 і $z=c$,

$$
\begin{gathered}
N_{1}=N_{2}=N_{3}=N_{4}=0, \text { тоді } N_{5}=\frac{1}{4 a b}(b+x)(a-y), N_{6}=\frac{1}{4 a b}(b+x)(a+y), \\
N_{7}=\frac{1}{4 a b}(b-x)(a+y), N_{8}=\frac{1}{4 a b}(b-x)(a-y) .
\end{gathered}
$$

Аналогічно можна отримати функції форм для інших граней елемента.

Якщо конвективний теплообмін має місце на кількох поверхнях скінченного елемента, тоді внесок поверхневого інтервалу в матрицю жорсткості дорівнює сумі внесків через кожну грань.

Аналогічно записуються поверхневий та об'ємний інтеграли у співвідношенні (4) за умови, що $Q$ і $\theta$ сталі величини. 
Температурний стан розглянутої конструкції при коефіцієнтах Ляме $\lambda, \mu$ i коефіцієнті лінійного теплового розширення $\alpha_{t}$, залежних від температури та від координат, описувався рівнянням рівноваги, яке у векторній формі має вигляд [3]:

$\mu \Delta \bar{u}+(\lambda+\mu) \operatorname{grad}(\operatorname{div} \bar{u})+2 \operatorname{grad} \mu \Pi_{\varepsilon}+\operatorname{grad} \lambda \cdot \operatorname{div} \bar{u}-\operatorname{grad}(3 \lambda+2 \mu) \alpha_{t} t=0$,

де $\bar{u}=\left\{\begin{array}{l}u \\ v \\ w\end{array}\right\}$ - вектор переміщень, $\lambda=\frac{v E}{(1+v)(1-2 v)}, \quad \mu=\frac{E}{2(1+v)}, E-$ модуль пружності, $v$ - коефіцієнт Пуасона, $\Pi_{\varepsilon}-$ тензор деформацій.

Граничні умови на поверхні можуть задаватися або у переміщеннях $u=\varphi_{i}(x, y, z)$, або у напруженнях $\sigma_{i j} n_{j}=F_{i}(x, y, z)$, де $\sigma_{i j}-$ компонент тензора напружень, $F_{i}$ - складові вектора поверхневих сил.

Фізичні рівняння закону Гука 3 для ортотропних матеріалів у відповідності до [5] мають вид

$$
\begin{array}{cc}
\varepsilon_{x}=\frac{1}{E_{x}} \sigma_{x}-\frac{v_{y x}}{E_{y}} \sigma_{y}-\frac{v_{z x}}{E_{z}} \sigma_{z}+\alpha_{t x} \Delta t, & \gamma_{y z}=\frac{1}{G_{y z}} \tau_{y z}, \\
\varepsilon_{y}=-\frac{v_{x y}}{E_{x}} \sigma_{x}+\frac{1}{E_{y}} \sigma_{y}-\frac{v_{z y}}{E_{z}} \sigma_{z}+\alpha_{t y} \Delta t, & \gamma_{x z}=\frac{1}{G_{x z}} \tau_{x z}, \\
\varepsilon_{z}=-\frac{v_{x z}}{E_{x}} \sigma_{x}-\frac{v_{y z}}{E_{y}} \sigma_{y}+\frac{1}{E_{z}} \sigma_{z}+\alpha_{t z} \Delta t, & \gamma_{x y}=\frac{1}{G_{x y}} \tau_{x y},
\end{array}
$$

де $G_{x y}, G_{x z}, G_{y z}$ - модулі зсуву між відповідними осями координат, $\gamma_{x y}, \gamma_{x z}, \gamma_{y z}-$ деформації зсуву, $\tau_{x y}, \tau_{x z}, \tau_{y z}$ - напруження зсуву, $\Delta t=t-t_{0}, t_{0}$ - початкове значення температури.

Узагальнений закон Гука для анізотропного матеріалу відносно вектору напружень використовуємо в матричному вигляді [5]

$$
\{\sigma\}=[D]\{\varepsilon\}-[D]\left\{\varepsilon_{0}\right\}
$$

де $\{\sigma\}$ - вектор внутрішніх зусиль, $\{\varepsilon\}$ - вектор повної деформації, $\left\{\varepsilon_{0}\right\}$ - вектор температурної деформації, $[D]$ - матриця, компонентами якої є пружні константи.

Розрахунок напружено-деформованого стану конструкції, що розглядається, здійснювався за МСЕ, тому розрахункові рівняння були отримані за допомогою теореми про потенціальну енергію [3].

У загальному випадку повна потенціальна енергія П пружної системи складається 3 двох частин [10]: 3 енергії деформації $\Lambda$ і потенціальної енергії прикладених сил $W_{p}$

$$
\Pi=\Lambda+W_{p} .
$$

Робота зовнішніх сил $W$ протилежна за знаком їх потенціальної енергії, $W=-W_{p}$, так що співвідношення (7) має вигляд

$$
\Pi=\Lambda-W .
$$

Після розділення досліджуваної конструкції на елементи, рівність (8) буде виглядати як сума 


$$
\Pi=\sum_{e=1}^{E}\left(\Lambda^{(e)}-W^{(e)}\right) .
$$

Скориставшись теоремою про потенціальну енергію, отримаємо з (9) наступну систему рівнянь

$$
\frac{\partial \Pi}{\partial\{u\}}=\sum_{e=1}^{E} \frac{\partial}{\partial\{u\}}\left(\Lambda^{(e)}-W^{(e)}\right)=0
$$

де $\{u\}$ - вектор вузлових переміщень дискретної моделі.

Енергія деформації нескінченно малого об’єму обчислюється за формулою

$$
d \Lambda=\frac{1}{2}\{\varepsilon\}^{T}\{\sigma\}-\frac{1}{2}\left\{\varepsilon_{0}^{t}\right\}^{T}\{\sigma\},
$$

$$
\begin{gathered}
\text { де }\{\varepsilon\}^{T}=\left[\varepsilon_{x x}, \varepsilon_{y y}, \varepsilon_{z z}, \gamma_{y z}, \gamma_{z x}, \gamma_{x y}\right],\{\sigma\}=\left\lfloor\sigma_{x x}, \sigma_{y y}, \sigma_{z z}, \tau_{y z}, \tau_{z x}, \tau_{x y}\right\rfloor, \\
\left\{\varepsilon_{0}^{t}\right\}^{T}=\left[\alpha_{x x} \Delta t, \alpha_{y y} \Delta t, \alpha_{z z} \Delta t, 0,0,0\right] .
\end{gathered}
$$

Повну енергію деформації скінченного елементу отримаємо як наслідок інтегрування (10) за об'ємом елемента $V^{(e)}$

$$
\Lambda^{(e)}=\frac{1}{2} \int_{V^{(e)}}\left(\{\varepsilon\}^{T}\{\sigma\}-\left\{\varepsilon_{0}^{t}\right\}^{T}\{\sigma\}\right) d V .
$$

В результаті підстановки співвідношення (6) в (11) отримаємо рівняння

$$
\Lambda^{(e)}=\frac{1}{2} \int_{V^{(e)}}\left(\{\varepsilon\}^{T}[D]\{\varepsilon\}-\{\varepsilon\}^{T}[D]\left\{\varepsilon_{0}\right\}-\left\{\varepsilon_{0}^{t}\right\}^{T}[D]\{\varepsilon\}+\left\{\varepsilon_{0}^{t}\right\}^{T}[D]\left\{\varepsilon_{0}\right\}\right) d V .
$$
вигляді

Потенціальну енергію масових і прикладених поверхневих сил запишемо у

$$
W^{(e)}=\int_{V^{(e)}}(X u+Y v+Z w) d V+\int_{S^{(e)}}\left(P_{x} u+P_{y} v+P_{z} w\right) d S,
$$

де $\{X, Y, Z\}$ - вектор об'ємних навантажень, $\left\{P_{x}, P_{y}, P_{z}\right\}-$ вектор поверхневих навантажень.

У відповідності до МCE [10] проекції вектора переміщень представимо наступним чином

$$
u=\sum_{i=1}^{m} N_{i} u_{i}, \quad v=\sum_{i=1}^{m} N_{i} v_{i}, \quad w=\sum_{i=1}^{m} N_{i} w_{i},
$$

де $u_{i}, v_{i}, w_{i}$ - вузлові значення компонентів вектора переміщень, $i$ - номери вузлів в елементі, $N_{i}$ - функції форми.

У векторному вигляді ці співвідношення запишемо наступним чином

$$
\{u\}=[N]\{U\},
$$

де $\{u\}$ - вектор вузлових переміщень. 
Вектор деформацій має вигляд

$$
\{\varepsilon\}=[B]\{u\},
$$

де $[B]$ - матриця, яка отримана диференціюванням матриці $[N]$.

Енергія деформації окремого елемента за допомогою (6) і (16) обчислюється за формулою

$$
\Lambda^{(e)}=\frac{1}{2} \int_{V^{(e)}} \Phi d V
$$

де $\Phi=\{U\}^{T}\left[B^{(e)}\right]^{T}\left[D^{(e)}\right]\left[B^{(e)}\right]\{U\}-2\{U\}^{T}\left[B^{(e)}\right]^{T}\left[D^{(e)}\right]\left\{\varepsilon_{0}^{(e)}\right\}+\left\{\varepsilon_{0}^{t}\right\}^{T}\left[D^{(e)}\right]\left\{\varepsilon_{0}^{t}\right\}$.

Останній доданок Ф не залежить від вузлових значень $\{U\}$, тому він не впливає на процес мінімізації і в подальших перетвореннях не розглядається.

За допомогою формул (13) і (15) обчислимо роботу зовнішніх сил

$$
W^{(e)}=\int_{V^{(e)}}\{U\}^{T}\left[N^{(e)}\right]^{T}\left\{\begin{array}{l}
x^{(e)} \\
y^{(e)} \\
z^{(e)}
\end{array}\right\} d V+\int_{S^{(e)}}\{U\}^{T}\left[N^{(e)}\right]^{T}\left\{\begin{array}{c}
P_{x}^{(e)} \\
P_{y}^{(e)} \\
P_{z}^{(e)}
\end{array}\right\} d S .
$$

Для мінімізації диференціюємо (9) за $\{u\}$ і прирівнюємо результат нулю. Отримаємо систему алгебраїчних рівнянь

$$
[K]\{U\}=\{F\}
$$

де $K=\sum_{e=1}^{E}\left[K^{(e)}\right],\{F\}=-\sum_{e=1}^{E}\left[f^{(e)}\right],[K]-$ глобальна матриця жорсткості,

$$
\begin{gathered}
\{F\} \text { - вектор правих частин системи (19), }\left[K^{(e)}\right]=\int_{V^{(e)}}\left[B^{(e)}\right]^{T}\left[D^{(e)}\right]\left[B^{(e)}\right] d V, \\
{\left[f^{(e)}\right]=-\int_{V^{(e)}}\left(\left[B^{(e)}\right]^{T}\left[D^{(e)}\right]\left[\varepsilon_{0}\right]-\left[N^{(e)}\right]^{T}\left\{\begin{array}{c}
x^{(e)} \\
y^{(e)} \\
z^{(e)}
\end{array}\right\}\right) d V-\int_{S^{(e)}}\left[N^{(e)}\right]^{T}\left\{\begin{array}{l}
P_{x} \\
P_{y} \\
P_{z}
\end{array}\right\} d S .}
\end{gathered}
$$

Матриця $[D]$ має розмір $6 \times 6$, iї елементами $є$ пружні константи матеріалу. Вона визначається за законом Гука

$$
\left\lfloor D^{*}\left\{\{\sigma\}=[D]\{\varepsilon\} \mid D^{*}\right]-[D]\left\{\varepsilon_{0}\right\} \mid D^{*}\right] .
$$

Тут $\left\lfloor D^{*}\right\rfloor$ - обернена до $[D]$ матриця, $\{\varepsilon\}=\left|D^{*}\right|\{\sigma\}\left\{\varepsilon_{0}\right\}$.

Для матеріалу з трьома площинами симетрії, фізико-математичні властивості яких, співпадають з осями декартової системи координат, матриця $\left[D^{*}\right]$ має вигляд 


$$
\left[D^{*}\right]=\left|\begin{array}{cccccc}
\frac{1}{E_{x}} & \frac{v_{y x}}{E_{y}} & -\frac{v_{x z}}{E_{z}} & 0 & 0 & 0 \\
-\frac{v_{x y}}{E_{x}} & \frac{1}{E_{y}} & -\frac{v_{y z}}{E_{z}} & 0 & 0 & 0 \\
-\frac{v_{x z}}{E_{x}} & \frac{v_{y z}}{E_{y}} & \frac{1}{E_{z}} & 0 & 0 & 0 \\
0 & 0 & 0 & \frac{1}{G_{x y}} & 0 & 0 \\
0 & 0 & 0 & 0 & \frac{1}{G_{y z}} & 0 \\
0 & 0 & 0 & 0 & 0 & \frac{1}{G_{x z}}
\end{array}\right|
$$

За розглянутим методом проводились розрахунки термонапруженого стану фундаментів під енергоблоком Запорізької АЕС. На рис. 2 наведена умовна схема фундаменту.

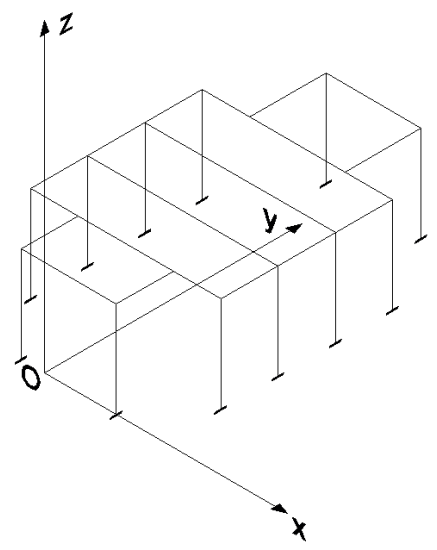

Рис. 2. Умовна схема фундаменту

В якості розрахункової схеми вибрана половина конструкції, тому що вона відносно осі $O Y$ зазнає осесиметричне теплове навантаження.

Глобальна система координат $X, Y, Z$ розташована так, щоб частина фундаменту, що розглядається, знаходилася у першому октанті. Місцева та глобальна система координат пов'язані залежностями, запозиченими із [10]:

$$
X=x^{\prime}+x_{u m}, \quad Y=y^{\prime}+y_{u m}, \quad Z=z^{\prime}+z_{u m} .
$$

В якості граничної умови для розрахунку температурних полів використані граничні умови першого роду [6].

Для визначення переміщень, що виникають від перепаду температур, задавалися наступні граничні умови: в місцях з'єднання колон і поперечних стін 3 нижньою та верхньою плитами (жорстке защемлення) $u=v=w=0$, в площині симетрії: $u=0, v \neq 0, w \neq 0$. Як відомо, в фундаментобудуванні застосовуються армовані бетони. Для розрахунку була прийнята модель конструкції, в якій жорсткість арматури фундаменту не враховувалась.

Результати розрахунків та експериментальні дані наведено на рисунках. На рис. 3 наведено розподіл розрахункових (крива 2) та експериментальних (крива 1) 
температур на ділянці фундаменту від генератора до збудника електромагнітних хвиль. На рис. 4 наведено результати розрахунку переміщень, які виникають за рахунок зміни температури на турбогенераторі, що працює, правої сторони (крива 2) та середини фундаменту (крива 1). На рис. 5 представлено усадку верхньої плити фундаменту для теплої (крива 1) та холодної (крива 2) пір року. На всіх рисунках ось абсцис відповідає довжині фундаменту.

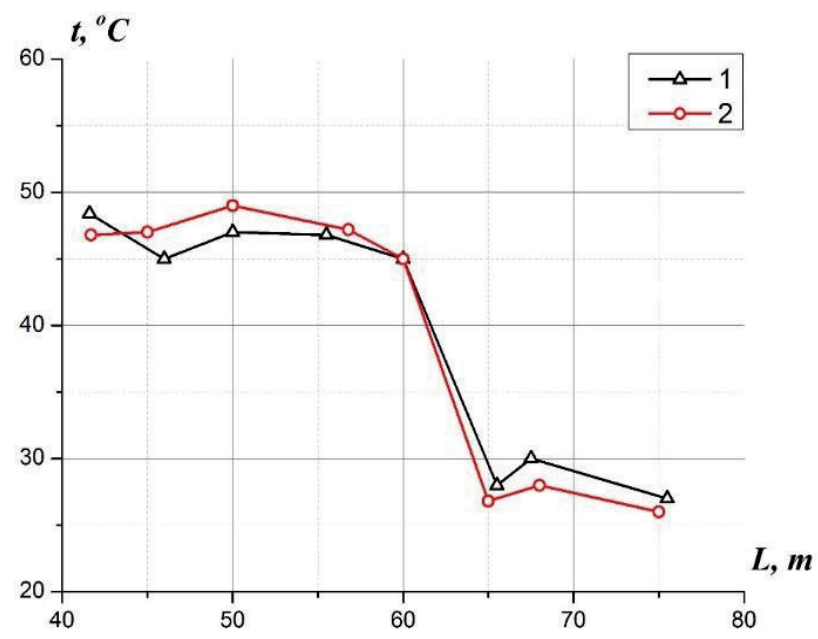

Рис. 3. Розподіл експериментальних (крива 1) і розрахункових (крива 2) температур

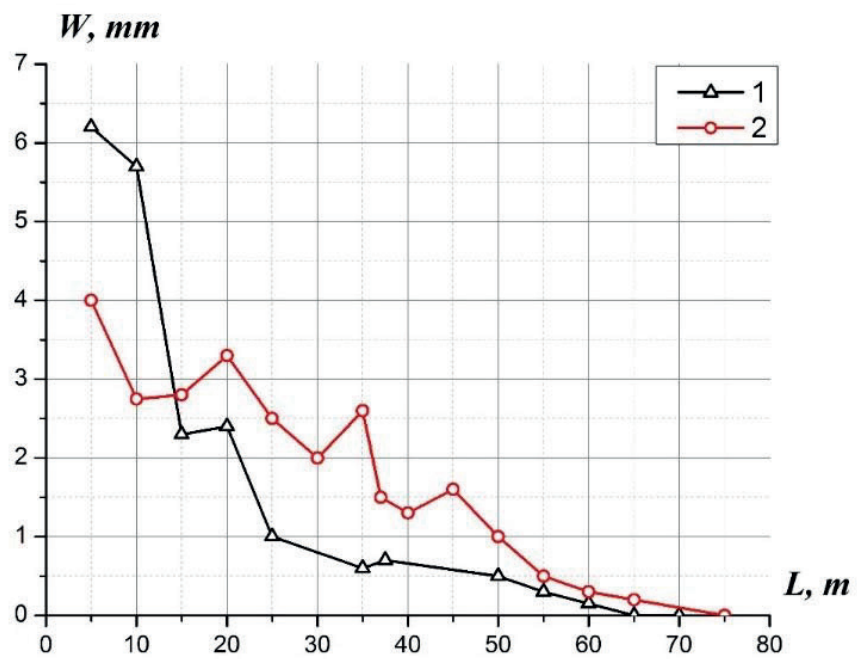

Рис. 4. Переміщення, викликані зміною температури на турбогенераторі, що працює, правої сторони (крива 2) та середини фундаменту (крива 1) 


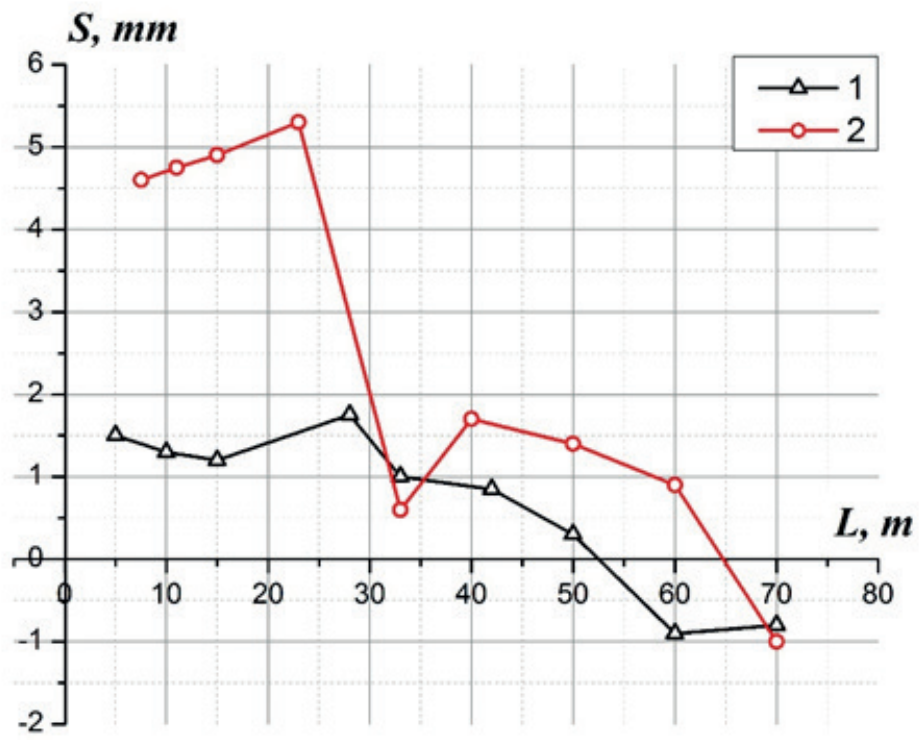

Рис. 5. Усадка верхньої плити фундаменту для теплої (крива 1) та холодної (крива 2) пір року

Висновок. Запропонований математичний метод дозволяє розв'язувати задачі визначення термонапруженого стану фундаментів під енергообладнаннями великої потужності. Його також можна використовувати для мінімізації роботи на стадії проектування фундаментів турбогенераторів для атомних електростанцій для підвищення надійності їх експлуатації.

\section{Бібліографічні посилання}

1. Акимов, П. А. Об использовании аппроксимирующих сеток в дискретноконтинуальном методе конечных элементов для расчета строительных конструкций / П. А. Акимов, О. А. Негрозов // Computational Civil and Structural Engineering, Volumell, Issuer, 2015.

2. Васильева, М. В. Численное моделирование задач термоупругости для конструкции с внутренним источником / М. В. Васильева, П. Е. Захаров // Математические заметки СВФУ. - 2017. - № 3(24). - С. 52-64.

3. Коваленко, А. Д. Термоупругость / А. Д. Коваленко. - К.: Высшая школа, 1975. $150 \mathrm{c}$.

4. Карвацький, А. Я. Розв'язання нелінійної нестаціонарної задачі теплоелектропровідності методом скінченних елементів / А. Я. Карвацький, А. Ю. Педченко // Вісник Приазовського державного технічного університету. Серія: Технічні науки. - 2016. Вип. 32. - С. 205-215.

5. Лехницький, С. Г. Теория упругости анизотропного тела / С. Г. Лехницкий. - М.: Наука, 1977. - $416 \mathrm{c}$.

6. Лыков, А. В. Теория теплопроводности / А. В. Лыков. - М.: Высшая школа, 1967. $600 \mathrm{c}$.

7. Макаренков, С. А. Математична модель розрахунку термонапруженого стану фундаментних конструкцій / Є. А. Макаренков, М. В. Матяш, В. О. Сясев // XXXIII Міжнародна конференція «Розвиток науки в XXI столітті». - Харків. - 2018. - С. 86-92.

8. Макаренков, Е. А. Решение задачи теплопроводности для полого цилиндра / Е. А. Макаренков, А. В. Сясев, В. Ю.Клим // Вісник Херсонського технічного університету. - 2016. - Вип. 3(58). - С. 366-371. 
9. Сивцев, П. В. Численное исследование некоторых прикладных проблем расчета напряженно-деформированного состояния / П. В. Сивцев // Диссертация, Якутск, Северовосточный федеральный ун-т им. М.К. Амосова. - 2018. - 148 с.

10. Сегерлинд, Л. Применение метода конечных элементов / Л. Сегерлинд. - М.: Мир, 1979. -392 c.

Надійшла до редколегї 30.10.2019

УДК 669.162.266.242:

669.102.267.34.001.57

\author{
В. И. Елисеев ${ }^{1}$, А. П. Толстопят ${ }^{1}$, Л. А. Флеер ${ }^{1}$, \\ Ю. П. Совит ${ }^{1}$, А. Ф. Шевченко ${ }^{2}$, С. А. Шевченко ${ }^{2}$ \\ ${ }^{1}$ Днепровский национальный университет имени Олеся Гончара \\ ${ }^{2}$ Институт черной металлургии НАНУ, г. Днепр
}

\title{
ДВИЖЕНИЕ ДВУХФАЗНОГО ПОТОКА В ФУРМЕ
}

На основе теории двухфазных течений (газ - твердые частицы) рассмотрена задача движения потоков в производственных трассах для подачи сыпучего магния в расплав чугуна. Данная работа является в какой-то степени подытоживающей некоторый этап лабораторных экспериментальных исследований, исследований в промышленных условиях, а также теоретических разработок. Несмотря на большие успехи и широкое использование теории взаимопроникающих сред, являющейся основной идеей подхода к расчету многофазных течений и установления необходимых зависимостей при взаимодействии фаз, важным условием остается вопрос о силовом воздействии стенок канала на движущиеся частицы. Имеющиеся литературные данные позволяют делать оценки нужных параметров, однако для длинных производственных трасс с изменяющимися геометрическими характеристиками не снимается необходиость экспериментального определения этих параметров в конкретных условиях. Такие данные были получены в результате многолетней работы на произвдственных площадках Китая, они вошли в соответствующие коэффициенты, характеризующие взаимодействие твердых частиц со стенками канала. С помощью методов аппроксимации были определены подгоночные коэффициенты Бусройда, которые в результате численных расчетов уравнений дают возможность определять динамические характеристики потоков с удовлетворительной точностью. В работе показаны изменения скорости и температуры газа и движущихся частиц на всем протяжении трассы, включая основной участок - фурму, опущенную в расплав чугуна.

Ключевые слова: трасса, фурма, расплав чугуна, двухфазные потоки, коэффициенты сопротивления и теплопередачи.

На основі теорії двофазних течій (газ - тверді частинки) розглянуто задачу руху потоків у виробничих трасах для подачі сипучого магнію в розплав чавуну. Дана робота в якійсь мірі підсумовує певний етап, як лабораторних експериментальних досліджень, досліджень в промислових умовах, так i теоретичних розробок. Незважаючи на великі успіхи і широке використання теорії взаємопроникливих середовищ, що є основною ідеєю підходу до розрахунку багатофазних течій і встановлення необхідних залежностей при взасмодії фаз, важливою умовою залишасться питання про силові дії стінок каналу на рухомі частинки. Наявні літературні дані дозволяють робити оцінки корисних властивостей, проте для довгих виробничих трас 3 мінливими геометичними характеристиками не знімається необхідність експериментального визначення цих параметрів в конкретних умовах.

Елисеев В. И., Толстопят А. П., Флеер Л. А., Совит Ю. П., Шевченко А. Ф., Шевченко С. А., 2019 